\title{
Plantamajoside represses the growth and metastasis of malignant melanoma
}

\author{
YAN WANG ${ }^{1}$, MINGZHU LIU ${ }^{2}$, SHENGLAN CHEN $^{1}$ and QIN WU ${ }^{1}$ \\ ${ }^{1}$ College of Medical Technology, Jiangsu Vocational College of Medicine, Yancheng, Jiangsu 224000; \\ ${ }^{2}$ Department of Dermatology, Nanjing Integrated Traditional Chinese and Western Medicine Hospital \\ Affiliated to Nanjing University of Chinese Medicine, Nanjing, Jiangsu 210014, P.R. China
}

Received November 27, 2018; Accepted December 13, 2019

DOI: $10.3892 /$ etm.2020.8442

\begin{abstract}
Plantamajoside (PMS) has been shown to have anticancer effects and is the main compound of Plantago asiatica. The aim of the present study was to investigate the effects of PMS on malignant melanoma and its molecular mechanisms. The malignant melanoma cell line A2058 was treated with different concentrations of PMS $(0,20,80$ and $160 \mu \mathrm{g} / \mathrm{ml})$ for 24,48 or $72 \mathrm{~h}$, followed by cell viability detection using the Cell Counting Kit- 8 assay. The present results suggested that PMS inhibited cell viability in a dose-dependent manner. In addition, flow cytometry was used to analyze cell apoptosis, and Transwell assays were used to investigate cell migration and invasion. The present results suggested that PMS induced A2058 cell apoptosis, and inhibited cell invasion and migration in a dose-dependent manner. In order to study the molecular mechanism by which PMS inhibited malignant melanoma growth and metastasis, reverse transcription-quantitative PCR and western blotting were used to determine the expression levels of apoptotic-related genes and PI3K/AKT signaling pathway-related proteins. The present results indicated that PMS inhibited the protein and mRNA expression of $\mathrm{Bcl}-2$, and promoted the expression of Bax and caspase-3 in a dose-dependent manner. The protein expression level of phosphorylated-AKT was dose-dependently reduced by PMS treatment. Collectively, the present results suggested that PMS inhibited the invasion, migration and viability of malignant melanoma cells. In addition, PMS induced apoptosis by regulating the expression levels of apoptotic-related genes and the activation of the PI3K/AKT signaling pathway, thereby exerting anti-malignant melanoma effects.
\end{abstract}

Correspondence to: Dr Qin Wu, College of Medical Technology, Jiangsu Vocational College of Medicine, 283 Jiefang South Road, Yancheng, Jiangsu 224000, P.R. China

E-mail: wuqin201718@163.com

Key words: plantamajoside, malignant melanoma, apoptosis, invasion, migration, PI3K/AKT pathway

\section{Introduction}

The prevalence of skin cancer is increasing at an alarming rate, with $\sim 1$ million new cases discovered annually worldwide (1). Malignant cutaneous melanoma occurs as a result of dysregulated proliferation of melanocytes in the epidermis and is one of the most aggressive forms of cutaneous neoplasms $(2,3)$. Malignant melanoma has a high metastatic rate, thus it is considered to be the most severe skin cancer type (3-5). The mortality rate of melanoma accounts for $65 \%$ of skin cancer deaths, despite the incidence rate only representing approximately $3 \%$ of all skin cancer types (6). Skin cancer prognosis is poor and usually leads to mortality due to metastasis (1). The median survival time is 8 months, and the 5-year survival among patients with stage IV metastatic melanoma is only approximately $10 \%(7,8)$. Although there are many antimelanoma treatments, in many cases melanoma is treatment-resistant (1). Thus, malignant melanoma is difficult to successfully treat using conventional surgery and chemotherapeutics (1).

Plant compounds are being increasingly used to prevent and treat many diseases including tumors (9-11). A cross-sectional survey in the West Midlands in the UK found that a substantial number of patients with cancer are likely to be taking herbal medicine (12). Currently, over 60 herbal complexes are being studied as anticancer medicine (11). The clinically used plant-derived anticancer drugs can be divided into four important groups: Vinca, alkaloids, taxanes and podophyllotoxins (13). Therefore, it is feasible to find new Chinese herbal medicines that may inhibit melanoma metastasis (11).

Plantamajoside (PMS) is a major ingredient isolated from Plantago asiatica (14). PMS has long been applied in food and medicine (14). PMS exhibits anti-inflammatory and antioxidant properties $(15,16)$. PMS has been applied to the treatment of many diseases due to its protective effects against cadmium-induced renal injury (17), and its anti-inflammatory (15) and antifibrotic effects (18). Currently, the antitumor effects of PMS in esophageal squamous cell carcinoma have been studied (19). However, to the best of our knowledge, the effect of PMS on malignant melanoma remains unknown.

Therefore, the aims of the present study were to investigate the effect of PMS on malignant melanoma in vitro, and to 
examine the underlying mechanism by which PMS may affect malignant melanoma.

\section{Materials and methods}

Cell culture and treatment. The malignant melanoma cell line A2058 was obtained from the Institute of Basic Medical Sciences, Chinese Academy of Medical Sciences. Human primary epidermal melanocytes were obtained from the American Type Culture Collection (cat. no. ATCC PCS-200-013). A2058 cells were cultured in RPMI-1640 media (Gibco; Thermo Fisher Scientific, Inc.) containing 10\% FBS (HyClone; GE Healthcare Life Sciences) at $37^{\circ} \mathrm{C}$ with $5 \% \mathrm{CO}_{2}$ for $24 \mathrm{~h}$. Normal melanocytes were grown in RPMI-1640 (HyClone; GE Healthcare Life Sciences) containing 10\% FSB (HyClone; GE Healthcare Life Sciences), $100 \mathrm{U} / \mathrm{ml}$ penicillin and $100 \mu \mathrm{g} / \mathrm{ml}$ streptomycin (Beyotime Institute of Biotechnology) in a humidified incubator with $5 \% \mathrm{CO}_{2}$.

PMS was purchased from Sigma-Aldrich (purity $>99 \%$; Merck KGaA), and DMSO (Sigma-Aldrich; Merck KGaA) was used to dissolve PMS. For PMS treatment, A2058 cells and normal melanocytes were treated with different concentrations of PMS $(0,20,80$ and $160 \mu \mathrm{g} / \mathrm{ml})$ at $37^{\circ} \mathrm{C}$ for $0,24,48$ and $72 \mathrm{~h}$ respectively following which the cells were subjected to further experimentation.

Cell Counting Kit-8 (CCK-8) assay. The CCK-8 method was used to detect cell viability. The cell concentration of normal melanocytes or A2058 cells was adjusted to $1 \times 10^{4} / \mathrm{ml}$, and $100 \mu \mathrm{l}$ cell suspension was added to each well of the 96-well plates. Then, A2058 cells were treated with different concentrations of PMS $(0,20,80$ and $160 \mu \mathrm{g} / \mathrm{ml})$ at $37^{\circ} \mathrm{C}$ for $0,24,48$ and $72 \mathrm{~h}$. The 96 -well plates were cultured at $37^{\circ} \mathrm{C}$ with $5 \% \mathrm{CO}_{2}$ for $24 \mathrm{~h}$. Subsequently, $10 \mu \mathrm{l} \mathrm{CCK}-8$ reagent (Sigma-Aldrich; Merck KGaA) was added to each well according to the manufacturer's protocol. The absorbance at the wavelength of $450 \mathrm{~nm}$ was measured after $2 \mathrm{~h}$ of incubation at $37^{\circ} \mathrm{C}$ using an automatic enzyme-linked immune detector. The experiment was repeated three times, and data were normalized to the control group, which was cells without any PMS treatment.

Flow cytometry. After treatment with different concentrations of PMS $(0,20,80$ and $160 \mu \mathrm{g} / \mathrm{ml})$ at $37^{\circ} \mathrm{C}$ for $48 \mathrm{~h}$, $0.2 \%$ trypsin was used to digest the normal melanocytes or A2058 cells. Cells were then washed with PBS and fixed using the $70 \%$ ethanol overnight at $4{ }^{\circ} \mathrm{C}$. The apoptotic rate of the cells was detected using the Annexin V-FITC/PI kit (cat. no. 70-AP101-100; Hangzhou Multi Sciences Biotech Co., Ltd.) according to the manufacturer's instructions. The apoptotic rate of normal melanocytes was also measured using an AnncxinV-FITC/PI Apoptosis Detection kit (cat no. A211-01; Vazyme Biotech Co., Ltd.) as per the manufacturer's instructions. BD FACSCalibur ${ }^{\mathrm{TM}}$ flow cytometer (Beckman Coulter, Inc.) coupled with the CellQuest ${ }^{\mathrm{TM}}$ software (version 5.1; BD Biosciences) were used to measure the apoptotic rate of cells. The experiments were performed in triplicate.

Transwell assay. Polycarbonate filters (pore size, $8 \mu \mathrm{m}$; Corning, Inc.) were used for the Transwell assay. Chamber inserts pre-coated with $200 \mathrm{mg} / \mathrm{ml}$ of Matrigel at $37^{\circ} \mathrm{C}$ for $30 \mathrm{~min}$ were used for cell invasion detection, whilst chamber inserts without Matrigel were used for cell migration determination. The upper chamber was plated with $200 \mu$ l RPMI-1640 media (Gibco; Thermo Fisher Scientific, Inc.) containing $0.1 \%$ FBS and $1 \times 10^{5}$ A2058 cells treated with different concentrations of PMS $(0,20,80$ and $160 \mu \mathrm{g} / \mathrm{ml})$ at $37^{\circ} \mathrm{C}$ for $48 \mathrm{~h}$. The lower chamber was plated with $600 \mu \mathrm{l}$ RPMI-1640 media (Gibco; Thermo Fisher Scientific, Inc.) with $10 \%$ FBS. After $48 \mathrm{~h}$ incubation at $37^{\circ} \mathrm{C}$, cells in the lower chamber were fixed with 4\% paraformaldehyde (cat. no. P0099; Beyotime Institute of Biotechnology) at room temperature for $30 \mathrm{~min}$ and then stained with $0.5 \mathrm{ml} 0.1 \%$ crystal violet (cat. no. C0121; Beyotime Institute of Biotechnology) at room temperature for 15 min. migrated or invaded cells were then counted using a light microscope (five fields per chamber; magnification $\mathrm{x} 200$ ). Each Transwell assay was repeated in five independent experiments.

Reverse transcription-quantitative PCR. TRIzol reagent (Invitrogen; Thermo Fisher Scientific, Inc.) was used to extract the total RNA from A2058 cells. Total RNA was reverse transcribed into cDNAs using the temperature protocol of $70^{\circ} \mathrm{C}$ for $5 \mathrm{~min}, 37^{\circ} \mathrm{C}$ for $5 \mathrm{~min}$ and $42^{\circ} \mathrm{C}$ for $1 \mathrm{~h}$. PrimeScript RT reagent kit (Takara Biotechnology Co., Ltd.) was used according to the manufacturer's instructions. qPCR was performed to analyze cDNAs using a TaqMan Universal PCR Master Mix kit (Thermo Fisher Scientific, Inc.) following the manufacturer's instructions. Primer sequences used for PCR were as follows: GAPDH forward, 5'-GCACCGTCAAGG CTGAGAAC-3' and reverse, 5'-TGGTGAAGACGCCAG TGGA-3'; Bcl-2 forward, 5'-TTCTTTGAGTTCGGTGGG GTC-3' and reverse, 5'-TGCATATTTGTTTGGGGCAGG-3'; Bax forward, 5'-TCCACCAAGAAGCTGAGCGAG-3' and reverse, 5'-GTCCAGCCCATGATGGTTCT-3'; and caspase-3 forward, 5'-TGTGGCATTGAGACAGAC-3' and reverse, 5'-CACTTGCCATACAAACTA-3'. The thermocycling conditions used for the qPCR were as following: Initial denaturation at $95^{\circ} \mathrm{C}$ for $10 \mathrm{~min}$; followed by 35 cycles of $95^{\circ} \mathrm{C}$ for $15 \mathrm{sec}$ and $55^{\circ} \mathrm{C}$ for $40 \mathrm{sec} . G A P D H$ was used as the standardized control. $\Delta \mathrm{Cq}=$ Cqgene-Cqreference is the relative level of gene expression, and the fold change in gene expression was calculated by the $2^{-\Delta \Delta \mathrm{Cq}}$ method (20). The experiments were repeated in triplicate.

Western blotting. Total proteins were collected using RIPA lysis buffer (cat no. P0013E; Beyotime Institute of Biotechnology) following the manufacturer's instructions. A bicinchoninic acid assay kit (Pierce; Thermo Fisher Scientific, Inc.) was used to quantify the protein samples. Protein samples (40 $\mu \mathrm{g}$ per lane) were separated on $10 \%$ SDS-PAGE and electrophoretically transferred onto a PVDF membrane (EMD Millipore). After blocking with $5 \%$ skim milk for $2 \mathrm{~h}$ at room temperature, the membrane was incubated with primary antibodies: Anti-AKT (1:1,000; cat. no. 4691; Cell Signaling Technology, Inc.), anti-phosphorylated (p)-AKT (1:1,000; cat. no. 4060; Cell Signaling Technology, Inc.), anti-Bcl-2 (1:1,000; cat. no. 4223; Cell Signaling Technology, Inc.), anti-Bax (1:1,000; cat. no. 5023; Cell Signaling Technology, Inc.), anti-total caspase-3 

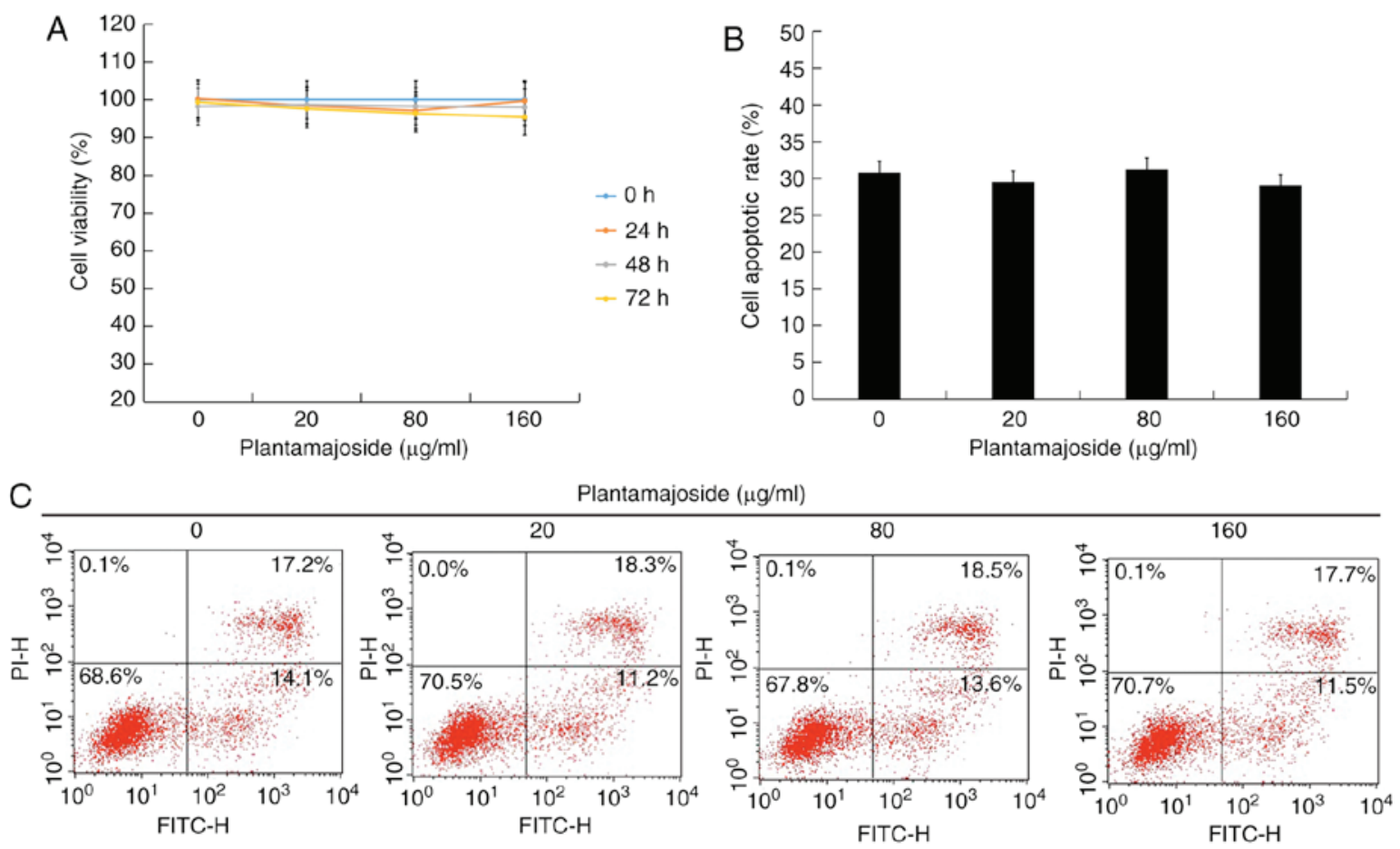

Figure 1. Effects of PMS on normal melanocytes. Normal melanocytes were treated with different concentrations of PMS $(0,20,80 \mathrm{and} 160 \mu \mathrm{g} / \mathrm{ml})$ for $48 \mathrm{~h}$. (A) Cell viability was assessed using a Cell Counting Kit-8 assay. (B) The apoptotic rate of A2058 cells was quantified from the (C) flow cytometry results. Data are presented as the mean \pm SD. PMS, plantamajoside.

(1:1,000; cat. no. 29629; Cell Signaling Technology, Inc.) and anti- $\beta$-actin $(1: 1,000$; cat. no. 4970; Cell Signaling Technology, Inc.), overnight at $4^{\circ} \mathrm{C}$. Then, the membranes were incubated with horseradish peroxidase-conjugated secondary antibody (1:1,000; cat. no. 7074; Cell Signaling Technology, Inc.) at room temperature for $2 \mathrm{~h}$. Protein bands were visualized using chemiluminescent ECL reagent (EMD Millipore) and quantified by densitometry (QuantityOne 4.5.0 software; Bio-Rad Laboratories, Inc.).

Statistical analysis. Data are presented as the mean \pm SD of $\geq 3$ independent experiments. One-way ANOVA followed by Tukey's post hoc test was used for comparison between groups. All data analyses were performed with SPSS 17.0 software (SPSS, Inc.). $\mathrm{P}<0.05$ was considered to indicate a statistically significant different.

\section{Results}

No significant effects of PMS on normal melanocytes. To investigate the effect of PMS on malignant melanoma cells, the present study examined the effect of PMS on normal melanocytes. After treatment with different concentrations of PMS $(0,20,80$ and $160 \mu \mathrm{g} / \mathrm{ml})$ for $0,24,48$ and $72 \mathrm{~h}$, cell viability was determined. The present results suggested that there were no significant effects of PMS on the viability of normal melanocytes (Fig. 1A). In addition, after treatment with different concentrations of PMS $(0,20,80$ and $160 \mu \mathrm{g} / \mathrm{ml})$ for $48 \mathrm{~h}$, the apoptotic rate of normal melanocytes was also investigated. The present results suggested that PMS had no effect on normal melanocyte apoptosis (Fig. 1B and C).

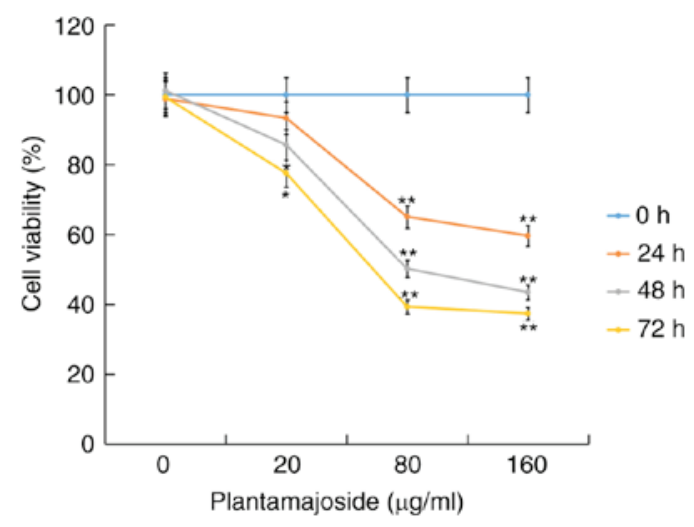

Figure 2. Effect of PMS on the viability of A2058 cells. Malignant melanoma cells were treated with different concentrations of PMS $(0,20,80$ and $160 \mu \mathrm{g} / \mathrm{ml})$ for $0,24,48$ and $72 \mathrm{~h}$. Then, the viability of cells was assessed using a Cell Counting Kit-8 assay. Data are presented as the mean $\pm \mathrm{SD}$. ${ }^{*} \mathrm{P}<0.05,{ }^{* *} \mathrm{P}<0.01$ vs. control group. PMS, plantamajoside.

PMS inhibits cell viability in a dose-dependent manner. The present study investigated the effect of PMS on the malignant melanoma cells. A2058 cells were treated with different concentrations of PMS $(0,20,80$ and $160 \mu \mathrm{g} / \mathrm{ml})$ for $0,24,48$ and $72 \mathrm{~h}$, then cell viability was measured using a CCK-8 assay. The CCK-8 assay results suggested that PMS inhibited A2058 cell viability in a dose-dependent manner (Fig. 2).

PMS induces cell apoptosis in a dose-dependent manner. After treatment with different concentrations of PMS $(0,20,80$ and $160 \mu \mathrm{g} / \mathrm{ml})$ for $48 \mathrm{~h}$, the apoptotic rate of 
Plantamajoside $(\mu \mathrm{g} / \mathrm{ml})$
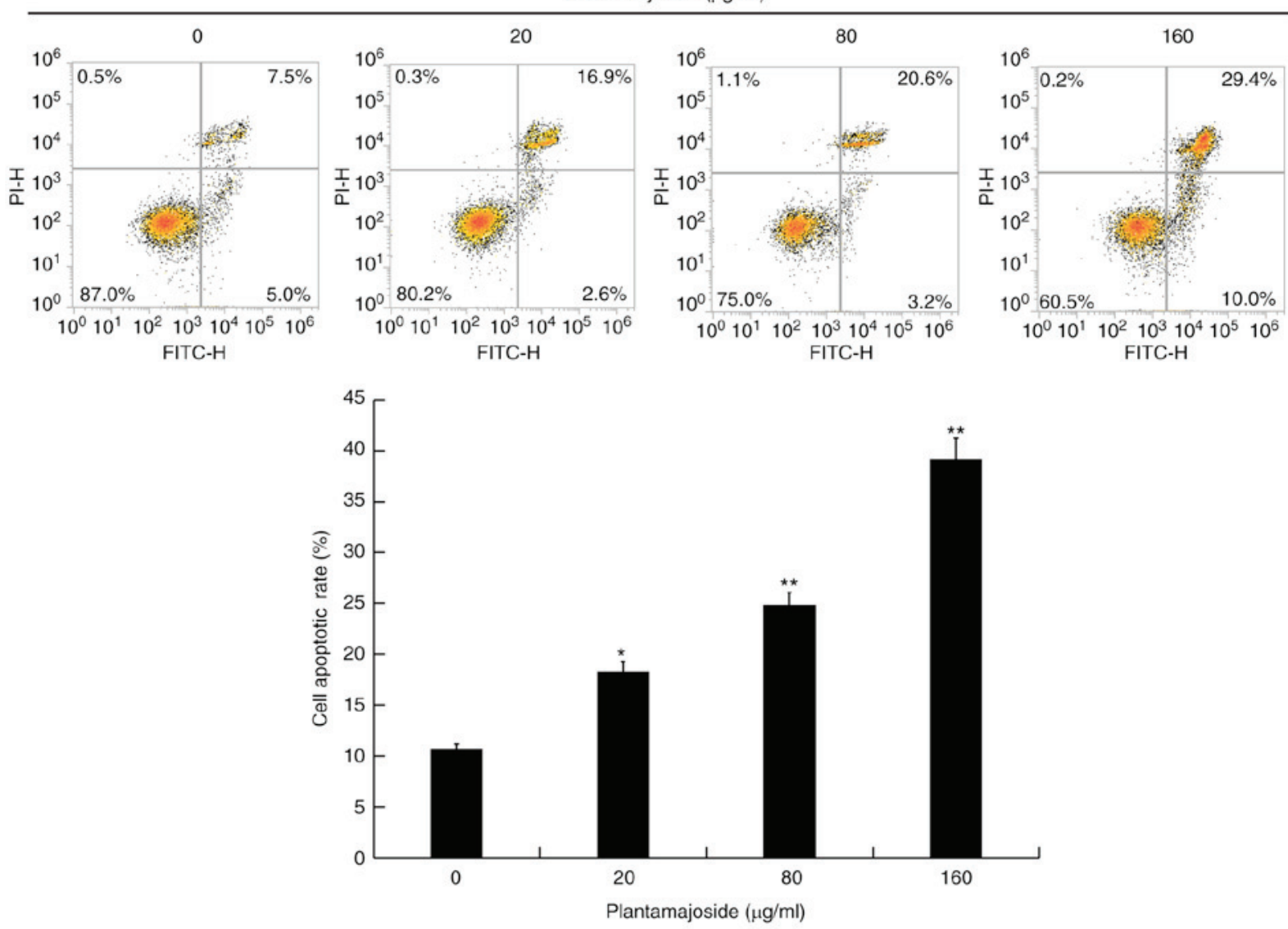

Figure 3. Effect of PMS on the apoptotic rate of A2058 cells. Malignant melanoma cells were treated with different concentrations of PMS ( $0,20,80$ and $160 \mu \mathrm{g} / \mathrm{ml})$ for $48 \mathrm{~h}$. Then an Annexin V-FITC/PI apoptosis detection kit was used to detect the apoptotic rate of A2058 cells. Data are presented as the mean \pm SD. ${ }^{*} \mathrm{P}<0.05,{ }^{* *} \mathrm{P}<0.01$ vs. control group. PMS, plantamajoside.

malignant melanoma cells was measured using Annexing V-FITC/PI staining. The present results suggested that the apoptotic rate of A2058 cells significantly increased after $48 \mathrm{~h}$ of PMS treatment, and that PMS induced apoptosis in a dose-dependent manner (Fig. 3).

PMS inhibits cell migration and invasion in a dose-dependent manner. Subsequently, after treatment with different concentrations of PMS $(0,20,80$ and $160 \mu \mathrm{g} / \mathrm{ml})$ for $48 \mathrm{~h}$, a Transwell assay was used to examine the effects of PMS on the migratory and invasive abilities of malignant melanoma cells. The Transwell assay results indicated that PMS inhibited cell migration (Fig. 4A) and invasion (Fig. 4B) in a dose-dependent manner.

Effect of PMS on the expression levels of apoptotic related genes and the PI3K/AKT signaling pathway. In order to study the mechanism by which PMS may affect A2058 cells, the cells were treated with different concentrations of PMS for $48 \mathrm{~h}$. Then, the expression levels of the apoptotic-related genes $B c l-2, B a x$ and caspase-3, and the relative proteins in the PI3K/AKT signaling pathway including AKT and p-AKT, were detected. The present results suggested that PMS inhibited the mRNA expression level of $\mathrm{Bcl}-2$, and promoted the mRNA expression levels of Bax and caspase-3 in a dose-dependent manner (Fig. 5A-C). Western blot analysis revealed that PMS inhibited the protein expression level of Bcl-2, and promoted the protein expression levels of Bax and caspase-3 in a dose-dependent manner (Fig. 5D-G). In addition, the protein expression level of p-AKT was inhibited by PMS treatment in a dose-dependent manner. (Fig. 5D and H). Collectively, the present results suggested that PMS may affect A2058 cells by impacting apoptotic related genes expression levels and the PI3K/AKT signaling pathway.

\section{Discussion}

Although the diagnosis and treatment of malignant melanoma is improving, the median survival time of patients diagnosed with malignant melanoma during metastasis is 6-9 months, the 5 -year survival rate is $<15 \%$ and the prognosis is still poor (21). Surgical removal of malignant melanoma is the preferred method of therapy, but treatment with radiation and/or chemotherapy is also used $(6,21)$. However, in the case of metastasis the cure rate is almost zero and only palliative treatment is available (22). In addition, immunotherapy of cytokines, as well as antibodies and BRAF inhibitors, are used in the treatment of malignant melanoma $(23,24)$. However, these therapies can cause serious side effects $(25,26)$. Therefore, due to the aggressiveness of melanoma and the complications associated with treatment, it is important to find alternatives to improve melanoma treatment. 

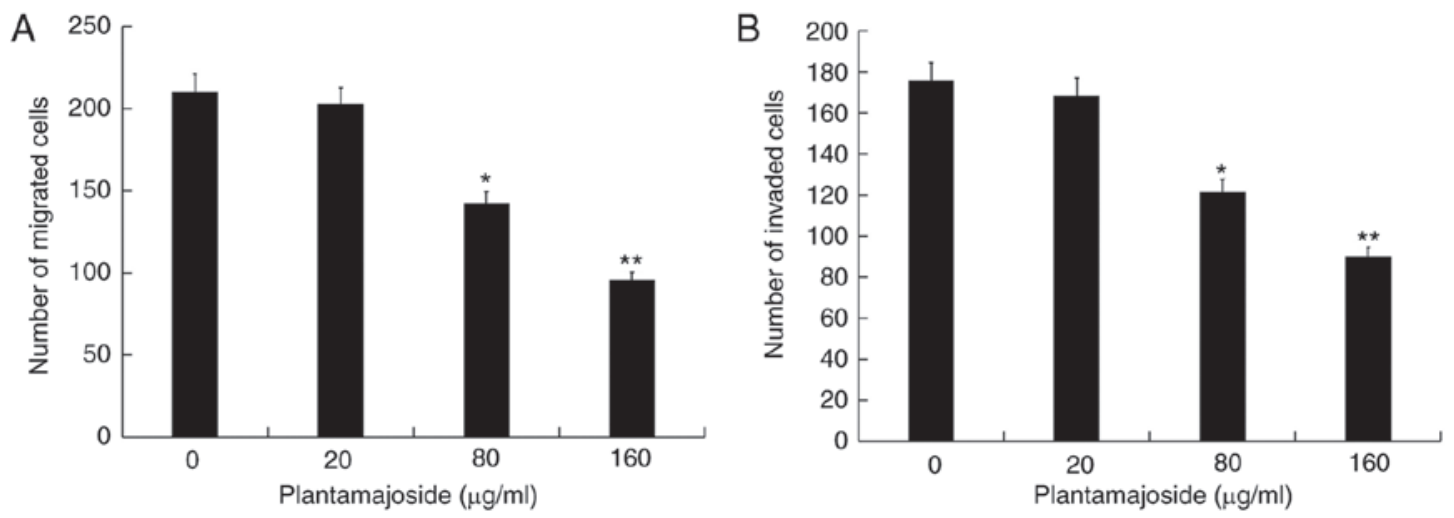

Figure 4. Effect of PMS on A2058 cell migration and invasion. Malignant melanoma cells were treated with different concentrations of PMS $(0,20,80$ and $160 \mu \mathrm{g} / \mathrm{ml})$ for $48 \mathrm{~h}$. Then the invasive and migratory abilities of cells were investigated using a Transwell assay. All experiments were performed in triplicate. (A) Effect of PMS on A2058 cell migration. (B) Effect of PMS on A2058 cell invasion. Data are presented as the mean \pm SD. ${ }^{*} \mathrm{P}<0.05$, ${ }^{* *} \mathrm{P}<0.01$ vs. control group. PMS, plantamajoside.
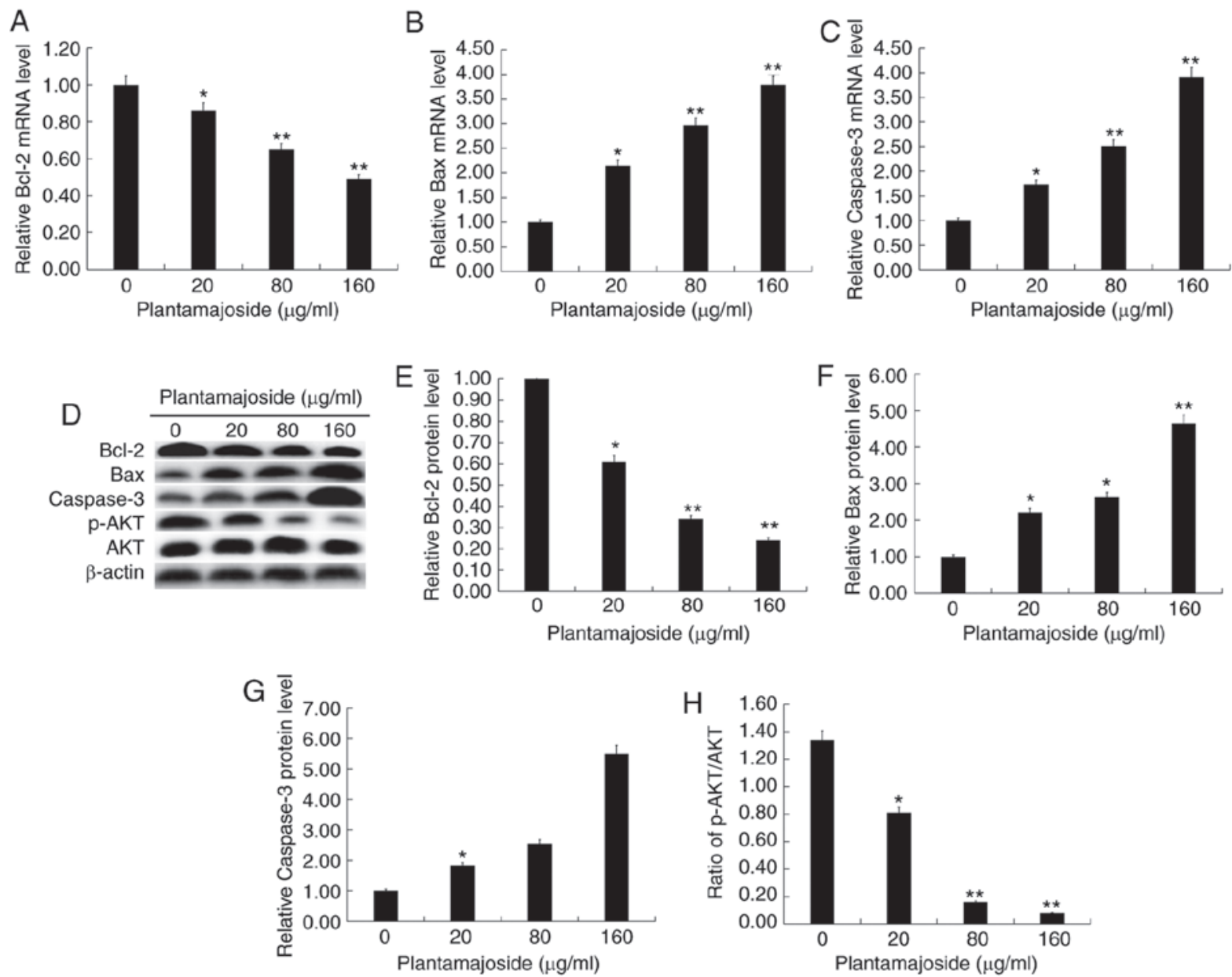

Figure 5. Effect of PMS on the PI3K/AKT signaling pathway related genes in A2058 cells. Malignant melanoma cells were treated with different concentrations of PMS $(0,20,80$ and $160 \mu \mathrm{g} / \mathrm{ml})$ for $48 \mathrm{~h}$. mRNA expression levels of (A) Bcl-2, (B) Bax and (C) caspase-3 were detected by reverse transcription-quantitative PCR. (D) Western blotting was used to investigate the protein expression levels of (E) Bcl-2, (F) Bax, (G) caspase-3 and (H) p-AKT/AKT. Data are presented as the mean $\pm \mathrm{SD} .{ }^{*} \mathrm{P}<0.05,{ }^{* *} \mathrm{P}<0.01$ vs. control group. PMS, plantamajoside; $\mathrm{p}$-, phosphorylated.

PMS has been previous found to exhibit antitumor properties (19). Therefore, the aims of the present study were to investigate the effect of PMS on malignant melanoma and its underlying mechanisms in vitro.
The present study examined the effect of PMS on normal melanocytes. After treatment with different concentrations of PMS $(0,20,80$ and $160 \mu \mathrm{g} / \mathrm{ml})$ for $48 \mathrm{~h}$, the present results suggested that there were no significant effects of PMS on 
viability and apoptosis of normal melanocytes. The present study also investigated the effect of PMS on malignant melanoma cells. A2058 cells were treated with different concentrations of PMS $(0,20,80$ and $160 \mu \mathrm{g} / \mathrm{ml})$ for $0,24,48$ and $72 \mathrm{~h}$, then cell viability was measured using a CCK- 8 assay. In line with a previous study (19), the present results suggested that the viability of A2058 cells was significantly inhibited by PMS treatment in a dose-dependent manner. Furthermore, the present results indicated that PMS induced cell apoptosis in a dose-dependent manner. Moreover, Pei et al (11) reported that PMS inhibited the growth and metastasis of breast cancer by inhibiting the activity of matrix metallopeptidase (MMP)-9 and MMP-2. The present study investigated the effect of PMS on the migration and invasion of malignant melanoma cells, and in line with results from a previous study (11), the present results indicated that PMS inhibited the migration and invasion of A2058 cells in a dose-dependent manner. Collectively, the present results suggested that PMS could effectively inhibit malignant melanoma cell growth and metastasis. Therefore, alternative treatments using PMS alone or in combination with other methods may be beneficial in the treatment of malignant melanoma.

A number of specific inhibitors targeting different signaling pathways have been introduced into preclinical trials such as the RAF inhibitors (RAF/MEK/ERK pathway) (27). A major research direction in the therapy of advanced melanoma is individualized molecular-targeted therapy, which specifically targets the key enzymes involved in the cell cancerous signaling pathway for targeted inhibition and different types of genetic mutations in patients (28). Among them, two survival signaling pathways RAS/mitogen-activated protein kinase and PI3K/AKT have been investigated (29-31). The PI3K/AKT signaling pathway is continuously activated in cancer cells and is closely related to cancer cell survival, proliferation, angiogenesis and invasion (32). Inhibition of the PI3K/AKT signaling pathway is expected to be an effective treatment for cancer (33). However, to the best of our knowledge, there is no research on the inhibition of the PI3K/AKT signaling pathway by PMS in melanoma cells. Therefore, the present study investigated the effect of PMS on the PI3K/AKT signaling pathway by examining the protein expression level of $\mathrm{p}-\mathrm{AKT}$ by western blotting. The present results indicated that PMS may inhibit malignant melanoma cell viability, invasion and migration. In addition, PMS may be able to induce apoptosis by regulating the expression levels of apoptotic-related genes and the activation of the PI3K/AKT signaling pathway, thereby exerting antimalignant effects on melanoma.

In conclusion, the present results suggested that PMS could effectively inhibit cell viability, migration and invasion, and induce apoptosis in malignant melanoma cells. The present results suggested that these effects were mediated by the regulation of apoptotic-related gene expression levels and activation of the PI3K/AKT signaling pathway. Therefore, PMS may be a promising new type of small molecule chemotherapy for treatment of malignant melanoma. However, the present study is only a preliminary study of the effect of PMS on melanoma and the effect of PMS on melanoma in vivo will need to be investigated in future studies. Follow-up experiments will need to continue to examine the effects of PMS in vivo in different species, as the effect of PMS on human malignant melanoma may be different to in vitro results. Therefore, the role of PMS in human malignant melanoma requires further experimental research.

\section{Acknowledgements}

Not applicable.

\section{Funding}

No funding was received.

\section{Availability of data and materials}

All data sets used and/or generated during the current study are available from the corresponding author on reasonable request.

\section{Authors' contributions}

YW contributed to study design, data collection, statistical analysis, data interpretation and manuscript preparation. MZL and SGC contributed to data collection and statistical analysis. QW contributed to data collection, statistical analysis and manuscript preparation. All authors read and approved the final manuscript.

\section{Ethics approval and consent to participate}

Not applicable.

\section{Patient consent for publication}

Not applicable.

\section{Competing interest}

The authors declare that they have no competing interests.

\section{References}

1. Sandhra MC, Alexandra APM, Nádia SVC, Isadora CC, Poliane C, de Oliveira LCA and Herman S: Synthesis and in vitro assessment of anticancer hydrogels composed by carboxymethylcellulose-doxorubicin as potential transdermal delivery systems for treatment of skin cancer. J Mol Liq 266: 425-440, 2018.

2. Haass NK, Smalley KSM, Li L and Herlyn M: Adhesion, migration and communication in melanocytes and melanoma. Pigment Cell Res 18: 150-159, 2005.

3. Ferreira LM, Cervi VF, Sari MHM, Barbieri AV, Ramos AP, Copetti PM, de Brum GF, Nascimento K, Nadal JM, Farago PV, et al: Diphenyl diselenide loaded poly( $\varepsilon$-caprolactone) nanocapsules with selective antimelanoma activity: Development and cytotoxic evaluation. Mater Sci Eng C Mater Biol Appl 91: $1-9,2018$

4. Coricovac D, Dehelean C, Moaca EA, Pinzaru I, Bratu T, Navolan D and Boruga O: Cutaneous melanoma-A long road from experimental models to clinical outcome: A review. Int J Mol Sci 19: pii: E1566, 2018.

5. Mou K, Ding M, Han D, Zhou Y, Mu X, Liu W and Wang L: miR-590-5p inhibits tumor growth in malignant melanoma by suppressing YAP1 expression. Oncol Rep 40: 2056-2066, 2018.

6. Dzwierzynski WW: Managing malignant melanoma. Plast Reconstr Surg 132: 446e-460e, 2013.

7. Shi Z, Lan B, Peng B, Wang X, Zhang G, Li X and Guo F: Combination therapy with $\mathrm{BH} 3$ mimetic and hyperthermia tends to be more effective on anti-melanoma treatment. Biochem Biophys Res Commun 503: 249-256, 2018. 
8. Garbe C, Eigentler TK, Keilholz U, Hauschild A and Kirkwood JM: Systematic review of medical treatment in melanoma: Current status and future prospects. Oncologist 16: 5-24, 2011.

9. Tariq A, Sadia S, Pan K, Ullah I, Mussarat S, Sun F, Abiodun OO, Batbaatar A, Li Z, Song D, et al: A systematic review on ethnomedicines of anti-cancer plants. Phytother Res 31: 202-264, 2017.

10. Chao J, Dai Y, Verpoorte R, Lam W, Cheng YC, Pao LH, Zhang W and Chen S: Major achievements of evidence-based traditional Chinese medicine in treating major diseases. Biochem Pharmacol 139: 94-104, 2017.

11. Pei S, Yang X, Wang H, Zhang H, Zhou B, Zhang D and Lin D: Plantamajoside, a potential anti-tumor herbal medicine inhibits breast cancer growth and pulmonary metastasis by decreasing the activity of matrix metalloproteinase- 9 and -2 . BMC Cancer 15 : $965,2015$.

12. Damery S, Gratus C, Grieve R, Warmington S, Jones J, Routledge P, Greenfield S, Dowswell G, Sherriff J and Wilson S: The use of herbal medicines by people with cancer: A cross-sectional survey. Br J Cancer 104: 927-933, 2011.

13. Khan T and Gurav P: PhytoNanotechnology: Enhancing delivery of plant based Anti-cancer drugs. Front Pharmacol 8: 1002, 2018

14. Samuelsen AB: The traditional uses, chemical constituents and biological activities of plantago major $L$. A review. J Ethnopharmacol 71: 1-21, 2000.

15. Liu F, Huang X, He JJ, Song C, Peng L, Chen T and Wu BL: Plantamajoside attenuates inflammatory response in LPS-stimulated human gingival fibroblasts by inhibiting PI3K/AKT signaling pathway. Microb Pathog 127: 208-211, 2019.

16. Han AR, Nam MH and Lee KW: Plantamajoside Inhibits UVB and Advanced Glycation End products-induced MMP-1 expression by suppressing the MAPK and NF- $\kappa \mathrm{B}$ pathways in $\mathrm{HaCaT}$ cells. Photochem Photobiol 92: 708-719, 2016.

17. Jung HY, Seo DW, Hong CO, Kim JY, Yang SY and Lee KW: Nephroprotection of plantamajoside in rats treated with cadmium. Environ Toxicol Pharmacol 39: 125-136, 2015.

18. Wang Y and Yan D: Plantamajoside exerts antifibrosis effects in the liver by inhibiting hepatic stellate cell activation. Exp Ther Med 18: 2421-2428, 2019

19. Li X, Chen D, Li M, Gao X, Shi G and Zhao H: Plantamajoside inhibits lipopolysaccharide-induced epithelial-mesenchymal transition through suppressing the NF- $\mathrm{BB} / \mathrm{IL}-6$ signaling in esophageal squamous cell carcinoma cells. Biomed Pharmacother 102: 1045-1051, 2018.

20. Livak KJ and Schmittgen TD: Analysis of relative gene expression data using real-time quantitative PCR and the 2(-Delta Delta C(T)) method. Methods 25: 402-408, 2001

21. Kozovska Z, Gabrisova V and Kucerova L: Malignant melanoma: Diagnosis, treatment and cancer stem cells. Neoplasma 63 : 510-517, 2016.
22. Markovic SN, Erickson LA, Flotte TJ, Kottschade LA, McWilliams RR, Jakub JW, Farley DR, Tran NV, Schild SE, Olivier KR, et al: Metastatic malignant melanoma. G Ital Dermatol Venereol 144: 1-26, 2009.

23. Franklin C, Livingstone E, Roesch A, Schilling B and Schadendorf D: Immunotherapy in melanoma: Recent advances and future directions. Eur J Surg Oncol 43: 604-611, 2017.

24. Greco A, Safi D, Swami U, Ginader T, Milhem M and Zakharia Y: Efficacy and adverse events in metastatic melanoma patients treated with combination BRAF plus MEK inhibitors versus BRAF inhibitors: A systematic review. Cancers (Basel) 11: pii: E1950, 2019.

25. Stahl T and Loquai C: Treatment side effects and follow-up of malignant melanoma. Radiologe 55: 136-143, 2015 (In German).

26. Cancedda S, Rohrer Bley C, Aresu L, Dacasto M, Leone VF, Pizzoni S, Gracis M and Marconato L: Efficacy and side effects of radiation therapy in comparison with radiation therapy and temozolomide in the treatment of measurable canine malignant melanoma. Vet Comp Oncol 14: e146-e157, 2016.

27. Bollag G, Hirth P, Tsai J, Zhang J, Ibrahim PN, Cho H, Spevak W, Zhang C, Zhang Y, Habets G, et al: Clinical efficacy of a RAF inhibitor needs broad target blockade in BRAF-mutant melanoma. Nature 467: 596-599, 2010.

28. Hauschild A, Agarwala SS, Trefzer U, Hogg D, Robert C, Hersey P, Eggermont A, Grabbe S, Gonzalez R, Gille J, et al: Results of a Phase III, Randomized, Placebo-controlled study of Sorafenib in combination with carboplatin and paclitaxel as second-line treatment in patients with Unresectable stage III or stage IV melanoma. J Clin Oncol 27: 2823-2830, 2009.

29. Nazarian R, Shi H, Wang Q, Kong X, Koya RC, Lee H, Chen Z, Lee MK, Attar N, Sazegar H, et al: Melanomas acquire resistance to B-RAF(V600E) inhibition by RTK or N-RAS upregulation. Nature 468: 973-977, 2010.

30. Davies MA: The role of the PI3K-AKT pathway in melanoma. Cancer J 18: 142-147, 2012

31. Yajima I, Kumasaka MY, Thang ND, Goto Y, Takeda K, Yamanoshita O, Iida M, Ohgami N, Tamura H, Kawamoto Y and Kato M: RAS/RAF/MEK/ERK and PI3K/PTEN/AKT signaling in malignant melanoma progression and therapy. Dermatol Res Pract 2012: 354191, 2012 .

32. Martini M, De Santis MC, Braccini L, Gulluni F and Hirsch E: PI3K/AKT signaling pathway and cancer: An updated review. Ann Med 46: 372-383, 2014.

33. Liu P, Cheng H, Roberts TM and Zhao JJ: Targeting the phosphoinositide 3-kinase pathway in cancer. Nat Rev Drug Discov 8: 627-644, 2009.

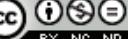

This work is licensed under a Creative Commons Attribution-NonCommercial-NoDerivatives 4.0 International (CC BY-NC-ND 4.0) License. 